Preprint Article

\title{
Intern Labour as Regenerative Precarisation in the Cultural and Creative Industries
}

Joshua Moody,

Irish Research Council Scholar,

Department of Sociology,

Maynooth University. 


\title{
Intern Labour as Regenerative Precarisation in the Cultural and Creative Industries
}

\begin{abstract}
Internships are a precarious labour practice often driven by a combination of labour market competition, desirable work, employer advantages and fictional expectations. This article is based on an empirical study of intern labour in the Cultural and Creative Industries in Ireland. The data consists of a survey of workers and interns, and interviews with interns past and present. Through approaching internships as a form of precarisation, and intern labour through the lens of 'fictional expectations', this article provides an analysis of intern labour as a form of regenerative precarisation through the self-reinforcing tendencies of action, subjectivity, discursive constructs and social structures. The labour market practice of interning creates discursive, normative and structural patterns of precarisation. These patterns in turn shape subjective and intersubjective expectations of work and life, impacting on the actions that individuals make and thus acting as drivers of further precarisation.
\end{abstract}

Keywords: Cultural and Creative Industries, Fictional Expectations, Internships, Individualisation of Risks, Regenerative Precarisation, Subjectivity.

Acknowledgements: This article greatly benefitted from the thoughtful and thorough insights and comments of Dr. Aphra Kerr, Prof. Seán Ó’Riain and Dr. Caroline O’Sullivan. The research underpinning this article was partly conducted with the support of Irish Research Council funding. 


\section{Introduction}

Social scientific studies of work are burgeoning, and much of the critical debate and empirical focus has been on the increasing 'precarisation' of working life and employment over the last four decades (Gill and Pratt, 2008; Kalleberg, 2009; 2011; 2012; Vallas and Prener, 2012; Standing, 2011; Alberti et al. 2018). Neologisms such as precarity, flexibilization and casualisation are now common vernacular as many seek to understand the extensive shifts permeating throughout work, employment and contemporary capitalist societies. Past research has shown aggregate growth in 'very atypical work' across the EU (Eurofound 2010), the disproportionate experience of precarious work for women, young people (or early career workers) and those of ethnic minorities, and the concentration of this work in lower paid sectors of economies. In addition, other work has focused on the growth of the phenomenon in relatively more privileged occupations such as professionals and managers (Brinkley 2013), and there has been a growing body of critical scholarship on precarious work and internships in the cultural and creative industries (CCI) (Ross 2007; Gill and Pratt 2008; Corrigan 2015). This article critically examines intern labour and the internship in the CCI as a form of regenerative precarisation where the interaction between individual and collective actors, subjectivities, discursive constructs and social structures drive the continuity, acceptance and (re)production of precarious conditions.

The precarity debate has come to denote the prevalence of financial instability, job insecurity, the decomposition of employment and social protections, and the experiences of growing uncertainty present in people's lives. More recently, Alberti et al. in the 2018 Work, Employment and Society special issue 'In, Against and Beyond Precarity', contend that the term has often been subjected to 'conceptual overstretch', they advocate instead for a focus on 'precarisation' as a process, as opposed to precarity as an all-encompassing concept which can lose its analytical coherency. This 
article builds on this perspective by critically analysing the internship and intern labour in the CCI as a potent form of precarisation, (re)producing distinct drivers and patterns that normalize and perpetuate the phenomenon. This article extends the reach of the work, employment and society dialogue by analysing internships in the creative economy, in turn directing our sociological gaze towards youth and early career experiences of work, employment and precarisation (Beck et al 2016). The internship represents one of the more extreme cases of precarious work. Despite its relatively inconspicuous nature and the lack of consolidated quantitative data, the prevalence of internships has been documented as an international trend over the last two decades (Lawton et al 2010; Perlin 2012). Much of the research has taken place in liberal market economies such as the US, UK, and Canada; this research extends this field by providing the first empirical study of CCI intern labour in the small open liberal market economy of Ireland.

The article makes a threefold contribution to critical research on intern labour and new understandings of work and employment in contemporary capitalism. Firstly, the empirical findings offer a plurality of perspectives from various sectors of the creative economy, providing accounts of work transitions, working conditions and worker subjectivities in the industries. Secondly, the article seeks to position CCI interns within wider conceptual efforts made by authors to document processes of precarisation (Alberti et al, 2018), and attempts to understand the sociological microfoundations of action under conditions of uncertainty (Beckert, 2013a; 2013b; 2016); this is achieved through the development of the concept of regenerative precarisation. Finally, it is the intention of this article to bring an empirically grounded account of early career workers in precarious circumstances into the ongoing dialogue on work and employment in these tempestuous times. The article is structured as follows: first, the literature on creative work, precariousness, intern labour and action in conditions of uncertainty will be reviewed; next, the 
data and methods used will be detailed; the findings will then be presented followed by the discussion where the primary aim is to show how action, subjectivity, discursive constructs and social structures interact to (re)produce precariousness, a dynamic which I call regenerative precarisation. The interaction of these four loci is presented through findings on work transitions in the cultural and creative labour market, experiences of intern labour and subjective rationalisations, interacting dynamics which shape the expectations of those entering the workforce and drive action.

\section{'Creative' Careers and Precarious Lives}

There has undoubtedly been a turn towards cultural and 'creative' work since the Dot-com boom and the 1990's (Banks et al. 2013). Taking root first across advanced western nations such as the UK ('Creative Industries Mapping Document'), Australia ('Creative Nation'), the US ('New Economy'), followed by similar trends across Europe, China and Canada to name a few (Ross 2009). During this period Ireland followed similar growth models as other advanced western nations, policy makers and industry interests embraced the popular rhetoric of the 'knowledgebased economy', with its emphasis on knowledge, creativity and high-tech innovation (GOI 2016; O'Riain 2000; 2004). The 'creative', 'digital' and 'knowledge' industries are increasingly acclaimed as areas of economic growth, value and future employment, and have been subsequently elevated to keystones of national and international industrial policy (Kerr 2007; DCMS, 1998; Ross, 2009; EU, 2010; OECD 2014). Following this 'creative turn', many researchers have drawn attention to the work and labour processes behind the highly economistic rhetoric underpinning the 'creative economy', and an extensive body of theoretical and empirical work has emerged in response. Knowledge, creativity and culture are seen as the 'new' driving sources of the economy, 
and the passionate, intuitive and flexible workers behind these activities are revered as ideal archetypes of the future of work. However, critical discourses on the nature of work in the 'creative economy' are beset with accounts of entrenched labour market precarity (de Peuter \& Cohen, 2015; de Peuter, 2011, 2014a, 2014b; Gill \& Pratt, 2008; Hesmondhalgh, 2010; McRobbie, 2002, 2012; Ross, 2009; Lorey, 2006; Standing, 2011; Lee, 2013; Vosko, 2002).

De Peuter and Cohen (2015) examine the emerging labour politics in the creative sectors; their work highlights the ascent of two key areas of contestation: precarious work practices and unpaid labour. These developments are exemplified through the embedding of intern labour as a normalised prerequisite to entering the CCI labour market. In many ways creative workers have been considered the 'poster boys and girls of the new precariat', their culture, commitment and passion for creative expression being the driving force against what is often poor pay and precarious working conditions in a highly individualised neoliberal labour market (Gill and Pratt, 2008). Creative work has become an interesting exemplar for changes to work organisation (Banks, 2017) and worker subjectivities. The project-based, informally networked labour markets of the creative economy are fertile ground for conditions of entrepreneurial competition and flexible, contingent labour markets where employers can mitigate responsibilities through the use of freelance work and unpaid labour. Such conditions often weaken labours position vis-a-vis capital and legitimise the growth of entrepreneurial subjectivities (Scharff 2016) and the individualisation of risks (Neff 2012). Emerging from almost two decades of 'creative industries' rhetoric, where a reductionist, highly economistic view of culture and creativity emerged, this article compliments the critical research done by CCI scholars by drawing our attention to the industries contentious rite of passage, the previously innocuous internship. 


\section{Intern Labour and Action in Conditions of Uncertainty}

Although Leonard, Halford \& Bruce (2015) highlight the lack of research and consideration for intern labour throughout academia, recent years have seen 'the politicisation of the previous innocuous subject of the intern' (de Peuter \& Cohen, 2015) and the growth of critical intern research (see Triple C 2015 special issue). The publication of Ross Perlin's 'Intern Nation' (2012) highlights the extent at which intern labour has become an integral part of the US labour market and an important rite of passage for graduate - work transitions. Internships have been shown to be at times a highly exploitative and often unregulated labour practice that can perpetuate social and economic inequalities; characteristics which become exacerbated when placed within the highly competitive and over-saturated labour market of the CCI (Corrigan, 2015). The mobilisation of intern activism initiatives such as Intern Aware (UK), The Carrot Workers Collective (UK), Precarious Workers Brigade (UK), Internocracy (UK) and Intern Labour Rights (US) have made the subject contentious by exposing the exploitative and, at times, dubious nature of the work involved in internships (C.W.C, 2011; Lawton \& Potter, 2010; Cohen and Peuter, 2015). Although there is a relative lack of scholarly research on the issue, studies of internships and unpaid work have been growing in recent years, and much of the research centres on creative work (Siebert and Wilson, 2013; Frenette, 2013; Percival and Hesmondhalgh, 2014; De Peuter et al., 2015; Corrigan, 2015; Lee, 2015; Shade and Jacobson, 2015; Jacobson and Shade, 2018), while some have examined other sectors of the economy (Chillas et al., 2015; Leonard et al., 2016; GrantSmith and McDonald, 2018). Despite this growing interest, much of the research has either been 
conducted with students on work placements or with interns from one sector (i.e video and film production, music etc). This article is based on data collected from interns and workers from across the CCI sectors, offering a pluralistic insight into contemporary trends and experiences.

As Kalleberg noted in his 2009 presidential address to the American Sociological Association 'work reveals much about the social order, how it is changing and the kind of problems and issues people (and their governments) must address'. The presence of intern labour is part of wider shifts in contemporary work and employment towards conditions of informality and precariousness. These changes result in the growing uncertainty of work and of experiences of job and income insecurity for workers. Building on Beckert's (2013a; 2013b; 2016) concept of 'fictional expectations' as the driver of action in conditions of uncertainty, the experiences of creative interns can be understood as decisions to persevere exploitation with the hopeful expectation of future employment and creative fulfilment. Similarly, Taylor (2012) and Corrigan (2015) understand creative work and interning to be future-oriented events, driven by the possibilities of selfactualization and occurring within wider structural conditions of uncertainty in work and employment. The accounts presented here very much apply to Duffy's (2016) work on 'aspirational labour' and Allan's (2019) 'volunteering as hope labour', where creative and informally networked work can lead to commitment from individuals based on promises of gaining future social and/or cultural capital. More often than not, the industries that use internships are in high demand and the work that they comprise strongly desired by educated and skilled entry level workers such as those in law, accountancy, media and advertising to name a few. Such desirable work is often met with high levels of passion, commitment and attachment from workers. Considering this and the hype around creative work, internships in the CCI are an exemplary case 
that can tell us much about where we are and where we may be going with regards to work, employment and precarity.

\section{Methods and Data}

The data used in this article are based on an empirical study of internships in the CCI in Ireland. It was a worker-centred study aimed at examining the experiences of working and interning in the industries, with a focus on the perceptions, opinions and choices of those engaged in the work. The research followed a two-phase process consisting of an initial survey and follow-up semistructured interviews with a selection of respondents.

The survey (see Table 1, appendix) was conducted with workers and interns (past, present, and prospective) from the CCI in Ireland. It was designed to locate those who have interned or are currently interning in the sectors. The combination of descriptive and exploratory questions recorded socio-demographic indicators (gender, age, education, occupation, sector), descriptions of work/intern conditions, perceptions of internships as a labour practice and why respondents thought they were used by employers. The data gathered provided valuable worker/intern profiles and accounts of work that enhanced the design of the thematic interview guide used in the second phase of data collection. The survey was disseminated online through popular industry and occupational community forums and social media platforms, shared through industry experts and academics and conducted face-to-face at a prominent creative industry conference (OFFSET) in Dublin. The survey was open to those working/interning within the sectors defined by the DCMS (1998) creative industries mapping document. Despite its contentiousness, it remains among the 
most utilised classifications of the 'creative industries', and as such it was used as a sectoral indicator and unit of analysis. A total of 47 participants completed the survey, consisting of 25 females and 22 males, with ages ranging from $21-37$. The sectoral spread of the sample is diverse, with workers in design (15), multimedia (9), online/digital media (8), advertising (4), video and film (3), music (2), software (2), animation (1), publishing (1), fashion (1) and photography (1). The survey included screening questions to filter for potential interviewees; of the 47 responses, 25 had interned or were currently an intern in the CCI and 22 had never worked as an intern. The survey data was analysed using SPSS statistical analysis software and open-ended answers were categorised into dominant themes.

Following the analysis of the survey data, nine semi-structured interviews (see Table 2, appendix) were conducted with respondents who had previously worked as an intern or were currently interning. The duration of interviews ranged from $30-50$ minutes. The interviews were transcribed, coded and analysed through a thematic framework of work transitions, experiences and subjectivity. The design of the interview guide was based on emergent topics arising from the analysis of the survey data and literature concerning intern labour, CCI work, and the sociology of work in $21^{\text {st }}$ century capitalism. The interviews were primarily concerned with examining the nature of the working conditions within CCI work and internships, industry access and worktransitions, the affective dimensions of these conditions on the workers and the strategic and contingent choices made by these workers through a complex mix of subjective rationalisations and fictional expectations. The interview sample contained 6 females and 3 males, originating from the advertising (2), online/digital media (2), multimedia (2), video and film (2) and design (1) sectors. In total, 16 internships and numerous work experience programmes and schemes were completed between the nine interviewees and the level of educational attainment was relatively 
high with all nine having completed a third level bachelor's degree in disciplines ranging from sound engineering, multimedia, product design, marketing, psychology, journalism, video \& film production and visual communication. The following sections present the findings and analysis which coalesce around industry access, experiences of work and worker subjectivities. Where interview quotes are used, pseudonyms have been added to ensure the confidentiality of the participants.

\section{Interning in the Creative Economy: Precarious Work and the Burden of Risks}

\section{Industry Access and Work Transitions}

When exploring the participants experiences of attempting to access the industry and transition into the workforce, the most evident finding from the survey was the prevalence of internships throughout the creative sectors. When asked if internships were common in the industries, almost $80 \%$, or 37 out of 47 respondents answered yes. These responses point to the ubiquity of internship positions throughout the labour market. The nine interviewees each possessed a third level qualification and the majority felt as though their education had reasonably prepared them for entering work in the CCI, although a lack of industry practical and organisational skills were expressed. Expectations of working in the sectors were strikingly similar and pointed towards a prevalence of internship positions. The majority of interviewees were "very aware" of the possibility of having to do an internship after graduating, the chances of getting a job were described as "slim to none" as there were "more unpaid internships than there were jobs" or "you needed two years' experience" for an entry level position. One of the participants explained that: 
'That's the culture, before you even graduate and look for work, as a student you're being offered out as free labour so it's just too easy for a company to take in someone for 6 weeks.' (Ryan, intern)

This in turn helped create a culture that legitimised the embedding of internships as a normalised practice and entry route in the industry, and reinforced discursive accounts which shaped expectations of work:

'I knew chances of me getting a job was slim to none straight out of college. The majority of my class have had to do internships in order to get jobs and some people are still interning now. I feel like it's just the norm to intern, maybe annoyingly so.' (Erica, intern) 'Yea I knew that was definitely what I had to do. Well before I started college I didn't know that, but the more I looked, everyone has to do an internship and they're going to have to kind of work for free and work for very little for a while.' (James, intern)

Most of the participants experienced significant difficulty in attempting to transition into the workforce, with one recalling that he had "to go into a company up in Dublin and basically beg for an unpaid internship". A downturn in job opportunities in the creative industries was highlighted by a 2008/09 graduate who also noticed an increase in internships throughout the industry following her completion of a masters in 2011. Similar responses were noted by the other interviewees with many stating that 'there were a lot less jobs' and a noticeable increase in unpaid internships:

'The only thing I did notice [when job searching] was most places were only looking for interns.' (Erica, intern) 
'I didn't see any jobs that were hiring anyone that didn't have experience in my field, every single thing was an internship or you needed two years full-time experience.' (James, intern)

The structural reality that confronted these prospective workers was one of a labour market saturated with internship positions, underpinned by a peer discourse describing the necessity of having to complete an internship to "get your foot in the door". Intense levels of competitiveness and rigorous employer demands were evident throughout the participants' transitional period to the labour market, employers were looking for "a jack of all trades" to cover a "very wide skillset".

'Up to this day I'm still kind of struggling with that, just with the job search thing, they keep on just asking for, for more.' (Rachel, intern)

'...people want you to have tons of experience, and that's why you kind of want to do an internship to build up that body of work. Even then when you do build it up, people want more and more from you.' (Saoirse, intern)

The search and application process for both jobs and internships were described as "really tough", "disheartening" and "soul destroying" as rejection was commonplace and the advertised positions seemed "completely unfeasible" due to low or no pay or the requirement of a minimum two years' experience. Some expressed feeling "hopeless" and "depressed" as they went through months of rejection. One of the participants experienced a sense of shame as she recalled feeling unconfident about talking to her friends and family about where she was in life. In another case, after completing two unpaid internships, the effects of the turbulent labour market transition were described as "fierce disheartening" and after 18 months of failed job searching, he made the decision to emigrate to Canada where he then did two more internships before gaining 
employment. Such precarious circumstances are not confined to work, living with the chronic uncertainty of contingent work and financial insecurity spills over into the everyday experience of life for those subjected to it. Issues of feasibility were raised by half of the participants, the concentration of jobs towards urbanised areas such as Dublin and Cork meant that many who were located outside urban centres were excluded from even considering positions as the majority were either unpaid, poorly paid and left no time for individuals to take up part time work to sustain themselves. However, three of those interviewed had a relatively smooth transition into the workforce, a persistent drive to look for internships during their time at college along with industry connections were identified as the instrumental factors in their success of finding work. Despite their affirmative efforts, all three considered themselves "very lucky".

\section{The Pressures and Pleasures of 'Creative' Intern Work}

In total, 16 internships (see Table 2 in appendix) were completed between the nine interviewees, with three adding that they had also completed numerous work experience programmes and schemes. Of those 16 positions, nine were unpaid, two covered expenses ranging from 30e100e/week, three were paid positions and the remaining two were unspecified. The duration of the internships ranged from 2 weeks to ten months, the majority were on a full-time basis while two participants reported working in excess of 50hrs/week and one was restricted to working 3days/week because of the difficulty of travel due to financial constraints. Financial pressures were the primary cause of contention, the issues surrounding pay were "a huge negative" which put some of the workers in "a position where they literally can't live". Descriptions of living precariously were recurring, many felt disheartened by the fact that they had studied for four or 
five years "on the poverty line" only to be confronted with the prospects of having to do internships which were either insufficiently paid or unpaid. The pervasive issues surrounding pay were the root cause of conflict and many interns feeling 'extremely anxious'. One participant described how working long hours for months with no pay triggered conflicts in her personal relationship, going on to say that "it made me sick, I broke down". Others felt like it was "demoralising not getting paid for your work", and that made them feel "anxious because I don't know how much money I have left to eat".

Over half of those interviewed mentioned the presence of "unofficial" and "unsociable" working hours where there was an undeclared expectation within the industry that workers would put in the long hours to prove themselves or see a project through to fruition, raising concerns for people with caring responsibilities. The pace and intensity at which the industry operates was signified as the driving factor behind these pressures and the unofficial demand for longer hours as "everyone wants stuff yesterday". Once the participants had eventually managed to obtain an internship position, a period of struggle, insecurity and uncertainty ensued for some as they experienced times of low self-esteem where they lost confidence in their abilities and felt as though they were not good enough. Insecurities were expressed by some as the instability of their position was made clear by watching and hearing of friends and peers being "let go" following their internships, it instilled a sense of fear and anxiety as "you know that could be you next". Throughout the course of the internships, the intensity and pressure inherent to the industry resulted in experiences of exhaustion over workloads for some; "stress" over deadlines and "frustration" over the quality of work. A number of those shared experiences which suggested that they were inextricably bound and reliant on the quality and peer recognition of their work and ideas. There was evidence of selfimposed obsession and pressure in relation to the work they produced, strong connections with 
their creative outputs meant that at times their sense of self-esteem was bound to the success or failure of their work. In a sense, the participants were made somewhat dependent on the reassurance of others of their own self-worth, with over half stating that getting good, positive feedback completely turned things around and gave them confidence.

The work the participants were required to do during their time interning was highly varied depending on the industry and employer, two of the women that had worked as interns in start-up companies reported that they had effectively taken on numerous roles such as marketing, design, web development, video production, office admin, a personal assistant and "everything else". One of the participants who had previously completed four internships claimed that most of his time was spent doing menial, trivial tasks such as answering the phone and spending "a lot of time just messing around at a computer and not really getting any experience". Five of those interviewed, however, expressed that they were learning and doing meaningful work, the main factor effecting the quality of their experience was the level of responsibility and opportunity given to them. Those who reported working on "real client work" and having a reasonable degree of "creative freedom" had on average a much more positive experience in their time as an intern. Each of the participants raised issues surrounding the exploitative nature of internships and called for "structure", "regulation", "job guarantees", limited duration, compensation and an adherence to training and learning. An urge was stressed "to be able to put value" to the work that interns do, the tasks undertaken by the interns in each of the cases were directly benefiting the companies by contributing to the production outputs and daily operations of the businesses. Whether it was the "dogs bodies work" or meaningful practical and technical work, the hours committed by these interns (see Table 1) materialised in tangible labour for the companies. 
Surprisingly, despite the numerous negative impacts experienced by those during their time interning, eight out of nine participants "really enjoyed it", they felt "stimulated", "interested", "inspired" and an "overwhelming sense of satisfaction" with one participant referring to her internship as the "best time of my life". The majority of those interviewed believed that working in the creative industries was "great", partially due to the interesting, engaging and varied work, described by one as an industry "like no other industry". Such an apparently contradictory dynamic begs the question: why do these workers describe exploitation, yet express satisfaction? An analysis of the subjective rationalisations employed by the workers provides some important context for answering this question.

\section{Rationalising Precarisation}

The data presented so far demonstrates circumstances where people were confronted with quite difficult prospects of entering the CCI labour market, forcing them to either do an internship, or numerous ones, or hold out in the hope of landing an entry level role. How these conditions and the decisions to persevere with them were rationalised showed how the development of certain subjectivities were critical in maintaining the precariousness of intern labour. When asked why they thought internships were common, the 47 survey respondents stated that free or cheap labour, the organisational structure and norms of the industry, and the usual trope of the need to gain experience were the primary reasons for the number of internships.

The most striking outcome of the data collected was that in the face of fierce competition, intense pressure and adverse conditions, the vast majority of those interviewed proclaimed to feel an overwhelming sense of enjoyment during their time as interns. The allure of the CCI and the 
"interesting", "engaging" and "exciting" work which it entails were a driving factor in the participants determination to "break into the industry". The industries were described as "fun", "cool", "creative" and "like no other", the nature of the work meant that with each project the workers felt a personal devotion and dedication to their creation. A number of participants expressed a love for what they do and reported feeling proud at various times throughout their experience, with some describing their time as "fulfilling" and "rewarding". A fascinating finding came in the form of the adoption of certain dispositions which effectively legitimised and reinforced the subjection of some participants to the relatively harsh environment which they attempted to navigate:

'If you work hard, if you keep the right mind-set and have a good attitude it will always work out and you will get to where you want to go' (Ryan, intern)

A reluctant sense of perseverance, enthusiasm, and acceptance were tools to rationalise their commitment, the self-reassurance that "it will always work out", the self-imposed obedience that "you're just going to have to accept that your superiors are always right" and the formation of a pernicious dialogue where:

'It is just the culture that you kind of have to embrace or it's not for you, if to do the hours is not for you, then you're not really suited for it.' (Saoirse, intern x2)

The presence of intern labour in the Irish CCI and its apparent acceptance as a prerequisite to entering the creative workforce was justified as "the culture", "the norm" and "protocol". Internships were "the done thing" and as the majority of participants claimed that "it's very hard to get your foot in the door" of the industry, one interviewee stated that: 
'I suppose I didn't really choose, I kind of had to do it out of necessity, I had to build up a portfolio to get to what I wanted to do and there just wasn't any paying jobs." (Saoirse, intern $\mathrm{x} 2$ )

Completing internships were considered a requirement in order to build up "the experience to finally go and get yourself a 'proper job"', experience was the decisive factor and the barrier to a standard, paid job. Many of those interviewed (8/9) believed their internships were "good experience" that "beefed up" their CV and gave them a "chance to break into the field" and "get some feel for the industry". Some reported making some "really good contacts", getting "exposure" and meeting some "really interesting people". The importance of networks was evident throughout the responses with some describing a lack of "contacts in the real world of work" and another explaining how contacts were a gatekeeper for her obtaining a paid internship position in a successful advertising firm. Following the analysis of the survey and the interviews, two things became apparent: first, the conditions of the work that these interns were involved in were exploitative, demanding and at times dubious and demeaning; and second, despite their knowledge of the labour market environment, these individuals made decisions to pursue and persevere these conditions in expectation of their imagined future outcome of employment and in aspiration of engaging in creative and 'fulfilling' work.

\section{Discussion}

This article presents an analysis of intern labour through the experiences of CCI interns in Ireland. The findings demonstrate: the prevalence of internship positions, internships as the industry norm, employer recruitment demands, the pressures and pleasures of 'creative' intern work, precarious 
conditions and labour exploitation, expressions of satisfaction with 'cool work', the legitimising of industry norms, consent of exploitation, individualising of risks and the reluctant acceptance of poor conditions. Studying internships and intern labour as an important manifestation and indicator of the contemporary and future trajectory of work, employment and precarisation has two primary benefits: firstly, internships are a growing phenomenon and often contain younger workers and early career workers attempting to enter the labour market in a respective field; secondly, internships as analysed here are understood as future oriented and, as they are currently organised, an inherently precarious labour practice that are grounded in fictional expectations of imagined outcomes. The implications are that those workers subjected to these circumstances will become the future workforce in various sectors of the economy, and their experiences and consent to what are exploitative and exclusionary practices can impact how work and employment are perceived in the future and how unequal power dynamics can become normalised. The calculations of the potential benefits of an internship (exposure, reputation, experience, 'better' CV's etc) can be viewed as a method of 'overlooking' for these precarious workers. This 'overlooking' of conditions of fundamental uncertainty can 'tranquilize' interns "against the paralyzing effects of having to [work] in unpredictable environments" (Beckert 2013: 234, emphasis added).

Approaching the action of these interns to commit to precarious work through the lens of fictional expectations provides insights into the subjectivities and behaviours of young and early career workers. However, these subjective rationalisations do not occur in isolation from the discursive, normative and structural contexts within which they take place. Vallas and Prener (2012: 338) contend that "politically and culturally rooted shifts in work expectations have the potential to recast the way workers think about and experience the employment relationship, with effects that can have powerful effects on the outcomes that obtain". The analysis laid out here shows that 
expectations of work in the CCI are shaped by social and cultural discursive constructs of "this is just how it is", but that these fictional expectations can obtain a causal efficacy not only through the discursive (stories and discourses etc) but through the organisation of social structures (Thompson and Harley 2012). This is evident in the very form of the internship as a work practice, but also in the recent changes in government active labour market policies in both Ireland (Murphy 2017) and the UK (Greer 2016) which have the effect of 'normalizing' precarious work (Rubery et al. 2018) and the exploitation of labour. Precarisation, when seen through the four loci of action, subjectivity, discursive constructs and social structures, can be observed as a regenerative process that (re)produces itself through its internal dynamics. In the case of the CCI intern, these dynamics manifest in actions driven by fictional expectations and desires, a discursive and normative framing of internships as "the done thing" and the structural realities of the prevalence of internship roles and the gradual unpredictability of work and life in $21^{\text {st }}$ century capitalism.

\section{Conclusion, Limitations and Future Recommendations}

This article presents internships and intern labour in the CCI as a form of regenerative precarisation where the interaction between action, subjectivity, discursive constructs and structural conditions (re)produce the phenomenon. Objective circumstances such as industry opportunities, labour market competition and the difficulties of gaining industry 'access' combined with the passion and commitment of entry level workers to 'do what I love' provides a cyclical pool of labour for the industry which is free, cheap, willing, and dependent. Directing our sociological gaze to the conditions and experiences of this burgeoning rite of passage, and the predominantly entry level workers that are subjected to it, is important if we are to gain a greater understanding of the future of work, employment and society. Entry level workers and the youth 
are disproportionately affected by informality and precarious work conditions (Beck et al. 2016). These findings point to the importance of external intervention in precarious work and employment conditions. The tendencies for those willing to work precariously and for employers willing to employ precariously are likely to sustain such conditions through this interdependent process. There is a two-directional dynamic occurring: increasing socio-economic uncertainty, informality and competitiveness push workers to subject themselves to precarious work; and imperatives of capital accumulation, cost-reduction strategies and an abundant pool of prospective workers push employers to make use of precarious employment practices. These two circumstances are then exacerbated by the discursive and subjective constructs that circulate about internships in the creative economy and beyond. It is difficult to envision a situation where this cycle can be broken internally via the capital-labour relation. Unionization of workers offers a proven route, although levels of collective representation among the CCI and wider 'new economy' sectors are low. Despite this, active intern rights groups such as Intern Aware and Intern Labour Rights have had some degree of success in politicising the subject.

The article also furthers new conceptual approaches to the study economic action in precarious times. By analysing internships as a process of precarisation (Alberti et al 2018) and applying Beckert's (2013a; 2013b; 2016) concept of 'fictional expectations', the self-re-enforcing tendencies of precarisation become evident and its temporal dynamics revealed. A limitation of this research has been its 'snapshot in time' approach; future research will benefit from the application of a longitudinal study of the impact of internships on workers, their subjectivities, and career outcomes. The circumstances of these workers embody much of the characteristics of the contemporary state of labour, work and employment. There is also an important temporal dynamic to such research. The drivers, actions and processes that shape the work and experiences of the 
future workforce in the present can reveal much about the potential future circumstances of work and employment in respective fields. In particular, this study of the dynamic of regenerative precarisation within the internship suggests that this practice may have implications for the normalisation of highly exploitative labour and an employee acquiescence for deep power imbalances in employment relations. What potential impact might these have on managing the expectations of these workers and on shaping the perspectives of future cultural producers and communicators?

\section{References}

Alberti G, Bessa I, Hardy K, et al. (2018) In, Against and Beyond Precarity: Work in Insecure Times. Work, Employment and Society 32(3): 447-457.

Allan K (2019) Volunteering as hope labour: the potential value of unpaid work experience for the un- and under-employed. Culture, Theory and Critique 60(1): 66-83.

Banks M and Hesmondhalgh D (2009) Looking for work in creative industries policy. International Journal of Cultural Policy 15(4): 415-430.

Banks M and O'Connor J (2009) After the creative industries. International Journal of Cultural Policy 15(4): 365-373.

Banks M and O'Connor J (2017) Inside the whale (and how to get out of there): Moving on from two decades of creative industries research. European Journal of Cultural Studies 20(6): 637-654.

Beck V, Brook P, Carter B, et al. (2016) Work, employment and society sans frontières : extending and deepening our reach. Work, Employment and Society 30(2): 211-219. 
Beckert J (2013a) Capitalism as a System of Expectations: Toward a Sociological Microfoundation of Political Economy. Politics \& Society 41(3): 323-350.

Beckert J (2013b) Imagined futures: fictional expectations in the economy. Theory and Society 42(3): 219-240.

Beckert J (2016) Imagined Futures: Fictional Expectations and Capitalist Dynamics. Cambridge, Massachusetts: Harvard University Press.

Bobek A, Pembroke S, Wickham J, et al. (2018) Living with Uncertainty: Social Implications of Precarious Work.

Chillas S, Marks A and Galloway L (2015) Learning to labour: an evaluation of internships and employability in the ICT sector: ICT sector internships and employability. New Technology, Work and Employment 30(1): 1-15.

Cohen N and De Peuter G (2015) Challenging Intern Nation: A Roundtable with Intern Labour Activists in Canada. tripleC: Communication, Capitalism \& Critique. Open Access Journal for a Global Sustainable Information Society 13(2): 587-598.

Collective C.W (2011) Surveying Internships: A Counter Guide to Free Labour in the Arts. London: CW Collective.

Corrigan T (2015) Media and Cultural Industries Internships: A Thematic Review and Digital Labor Parallels. tripleC: Communication, Capitalism \& Critique. Open Access Journal for a Global Sustainable Information Society 13(2): 336-350.

DCMS (1998) Creative industries mapping document. London: DCMS. 
De Peuter G (2011) Creative Economy and Labor Precarity: A Contested Convergence. Journal of Communication Inquiry 35(4): 417-425.

De Peuter G, Cohen NS and Brophy E (2015) Interrogating Internships: Unpaid Work, Creative Industries, and Higher Education. tripleC: Communication, Capitalism \& Critique. Open Access Journal for a Global Sustainable Information Society 13(2): 329-335.

De Peuter G, Cohen NS and Brophy E (2012) Interns of the Creative Industries, Unite! You Have Nothing to Lose-Literally. Briarpatch, 12 November.

De Peuter G (2014) Beyond the Model Worker: Surveying a Creative Precariat. Culture Unbound: Journal of Current Cultural Research 6(1): 263-284.

Duffy BE (2016) The romance of work: Gender and aspirational labour in the digital culture industries. International Journal of Cultural Studies 19(4): 441-457.

European Commision (2010) Green Paper: unlocking the potential of cultural and creative industries. Brussels: EU Commission.

Eurofound (2010) Flexible Forms of Work: 'Very Atypical' Contractual Arrangements. Dublin: Eurofound.

Flew T and Cunningham S (2010) Creative Industries after the First Decade of Debate. The Information Society 26(2): 113-123.

Frenette A (2013) Making the Intern Economy: Role and Career Challenges of the Music Industry Intern. Work and Occupations 40(4): 364-397.

Frenette A (2015) From Apprenticeship to Internship: The Social and Legal Antecedents of the Intern Economy. tripleC: Communication, Capitalism \& Critique. Open Access Journal for a Global Sustainable Information Society 13(2): 351-360. 
Government of Ireland (2016) Creative Ireland Programme 2017-2022. Dublin.

Gill R and Pratt A (2008) In the Social Factory?: Immaterial Labour, Precariousness and Cultural Work. Theory, Culture \& Society 25(7-8): 1-30.

Grant-Smith D and McDonald P (2018) Planning to work for free: building the graduate employability of planners through unpaid work. Journal of Youth Studies 21(2): 161-177..

Greer I (2016) Welfare reform, precarity and the re-commodification of labour. Work, Employment and Society 30(1): 162-173.

Gregg M (2011) Work's Intimacy. Cambridge: Polity Press.

Hassard J and Morris J (2018) Contrived Competition and Manufactured Uncertainty: Understanding Managerial Job Insecurity Narratives in Large Corporations. Work, Employment and Society 32(3): 564-580.

Hope, Sophie and Joanna Figiel. 2012. Intern Culture. Available at: https://www.artquest.org.uk/wpcontent/uploads/Intern-Culture-report.pdf. (Accessed 13 October 2018)

Hope S and Figiel J (2015) Interning and Investing: Rethinking Unpaid Work, Social Capital, and the "Human Capital Regime". tripleC: Communication, Capitalism \& Critique. Open Access Journal for a Global Sustainable Information Society 13(2): 361-374.

Ip I (2015) Negotiating Educated Subjectivity: Intern Labour and Higher Education in Hong Kong. tripleC: Communication, Capitalism \& Critique. Open Access Journal for a Global Sustainable Information Society 13(2): 501-508.

Jacobson J and Shade LR (2018) Stringtern : springboarding or stringing along young interns' careers? Journal of Education and Work 31(3): 320-337. 
Kalleberg AL (2009) Precarious Work, Insecure Workers: Employment Relations in Transition. American Sociological Review 74(1).

Kerr A (2007) From Boston to Berlin: Creativity and Digital Media Industries in the Celtic Tiger. In: My Creativity Reader: A Critique of Creative Industries. Amsterdam: Institute of Network Cultures. Available at: http://mural.maynoothuniversity.ie/1024/. (Accessed 10 May 2019)

Kuehn, K and Corrigan, TF (2013) 'Hope Labor: The Role of Employment Prospects in Online Social Production'. The Political Economy of Communication 1:1, 9-25.

Lawton K, IPPR, Potter D, et al. (2010) Why Interns Need A Fair Wage. London: Institute for Public Policy Research.

Lee D (2015) Internships, Workfare, and the Cultural Industries: A British Perspective. tripleC: Communication, Capitalism \& Critique. Open Access Journal for a Global Sustainable Information Society 13(2): 459-470.

Lee D (2012) The Ethics of Insecurity: Risk, Individualization and Value in British Independent Television Production. Television \& New Media 13(6): 480-497.

Leadbeater C (1999) Living on Thin Air: The New Economy. London: Viking.

Leonard P, Halford S and Bruce K (2016) 'The New Degree?' Constructing Internships in the Third Sector. Sociology 50(2): 383-399.

Littler J and Power N (2014) Life after work. Soundings 56(56): 67-80.

McKinlay A and Smith C (eds) (2009) Creative Labour: Working in the Creative Industries. Critical perspectives on work and employment. Basingstoke [England] ; New York: Palgrave Macmillan. 
McRobbie A (2002) From Holloway to Hollywood: Happiness at Work in the New Cultural Economy? In: Cultural Economy: Cultural Analysis and Commercial Life Cultural Economy: Cultural Analysis and Commercial Life. 1 Oliver's Yard, 55 City Road, London EC1Y 1SP United Kingdom: SAGE Publications Ltd, pp. 97-114.

McRobbie A (2016) Be Creative: Making a Living in the New Culture Industries. Cambridge, UK Malden, MA: Polity Press.

Miguel Carmo R, Cantante F and de Almeida Alves N (2014) Time projections: Youth and precarious employment. Time \& Society 23(3): 337-357.

Murphy MP (2017) Irish Flex-insecurity: The Post-crisis Reality for Vulnerable Workers in Ireland. Social Policy \& Administration 51(2): 308-327.

Neff G and Giovanni A (2007) The Competitive Privilege of Working for Free: Rethinking the Roles that Interns Play in Communication Industries. Paper presented at Annual Meeting of the American Sociological Association. Available at: https://tinyurl.com/y36xrhvl (Accessed 21 May 2019)

Neff G (2012) Venture Labor: Work and the Burden of Risk in Innovative Industries. Acting with technology. Cambridge, Mass: MIT Press.

Oakley K (2011) In its own image: New Labour and the cultural workforce. Cultural Trends 20(3-4): 281-289.

OECD (2014) Tourism and the Creative Economy. OECD Studies on Tourism. OECD.

Ó’Riain S (2000) The Flexible Developmental State: Globalization, Information Technology, and the “Celtic Tiger”. Politics \& Society 28(2): 157-193. 
Ó'Riain S (2004) The Politics of High-Tech Growth: Developmental Network States in the Global Economy. Structural analysis in the social sciences. New York: Cambridge University Press. Pembroke S (2018) Precarious work, precarious lives: how policy can create more security. Foundation for European Progressive Studies.

Percival N and Hesmondhalgh D (2014) Unpaid work in the UK television and film industries: Resistance and changing attitudes. European Journal of Communication 29(2): 188-203.

Perlin R (2012) Intern Nation: How to Earn Nothing and Learn Little in the Brave New Economy. Updated paperback ed. London: Verso.

Ross A (2009) Nice Work If You Can Get It: Life and Labor in Precarious Times. NYU series in social and cultural analysis. New York: New York University Press.

Rubery J, Grimshaw D, Keizer A, et al. (2018) Challenges and Contradictions in the 'Normalising' of Precarious Work. Work, Employment and Society 32(3): 509-527.

Scharff C (2016) The Psychic Life of Neoliberalism: Mapping the Contours of Entrepreneurial Subjectivity. Theory, Culture \& Society 33(6): 107-122.

Shade LR and Jacobson J (2015) Hungry for the Job: Gender, Unpaid Internships, and the Creative Industries. The Sociological Review 63(1): 188-205.

Siebert S and Wilson F (2013) All work and no pay: consequences of unpaid work in the creative industries. Work, Employment and Society 27(4): 711-721.

Smith V (2010) Review article: Enhancing employability: Human, cultural, and social capital in an era of turbulent unpredictability. Human Relations 63(2): 279-300.

Standing G (2011) The Precariat: The New Dangerous Class. London: Bloomsbury. 
Taylor S (2012) The Meanings and Problems of Contemporary Creative Work. Vocations and Learning 5(1): 41-57.

Taylor S and Littleton K (2012) Contemporary Identities of Creativity and Creative Work. Farnham; Burlington, Vt: Ashgate.

Thompson P and Harley B (2012) Beneath the Radar? A Critical Realist Analysis of 'The Knowledge Economy' and 'Shareholder Value' as Competing Discourses. Organization Studies 33(10): $1363-1381$.

Vallas S and Prener C (2012) Dualism, Job Polarization, and the Social Construction of Precarious Work. Work and Occupations 39(4): 331-353. 


\section{Appendix}

\begin{tabular}{|l|l|}
\hline \multicolumn{1}{|c|}{ Characteristics } & \multicolumn{1}{|c|}{ \% of Sample (n47) } \\
\hline \begin{tabular}{|l|l|} 
Female \\
Male
\end{tabular} & $53 \%$ \\
\hline Internship & $47 \%$ \\
Yes & $53 \%(60 \%$ Female, $40 \%$ Male) \\
No & $47 \%$ \\
\hline Education & \\
Postgraduate Degree & $21 \%$ \\
Honours Bachelor Degree & $51 \%$ \\
Ordinary Bachelor Degree & $21 \%$ \\
Apprentice or Certificate & $2 \%$ \\
Secondary Level & $2 \%$ \\
\hline Sector & \\
Design & $32 \%$ \\
Multimedia & $19 \%$ \\
Online/Digital Media & $17 \%$ \\
Advertising & $8.5 \%$ \\
Video \& Film & $6 \%$ \\
Music & $4 \%$ \\
Software & $4 \%$ \\
Animation & $2 \%$ \\
Other (fashion, photography, publishing) & $6 \%$ \\
\hline
\end{tabular}

Table 1: Survey responses. 


\begin{tabular}{|c|c|c|c|c|}
\hline Interns & Weekly Hours & Duration & $\begin{array}{l}\text { Total } \\
\text { Hours }\end{array}$ & Compensation \\
\hline Iris Intern 1 & 40/week & 10 months & 1,600 hours & Unpaid \\
\hline \multirow[t]{2}{*}{$\begin{array}{c}\text { Saoirse Intern } 2 \\
(\mathrm{x} 2)\end{array}$} & 35/week & 9 months & $\begin{array}{l}1,260+ \\
\text { hours }\end{array}$ & Unpaid \\
\hline & 40+/week & 3 months & $480+$ hours & Unpaid (hired) \\
\hline $\begin{array}{c}\text { Rachel Intern } 3 \\
(\mathrm{x} 2)\end{array}$ & $65+/$ week & 3 months & 810 hours & Unpaid (travel expenses) \\
\hline Ryan Intern 4 & 50avg/week & 4 months & 800 hours & Unpaid (travel expenses) \\
\hline \multirow{2}{*}{$\begin{array}{l}\text { Kevin Intern } 5 \\
(\mathrm{x} 4)\end{array}$} & 40/week & 4 months & 640 hours & Unpaid \\
\hline & $30 /$ week & 6 months & 720 hours & Unpaid \\
\hline James Intern 6 & 42.5/week & 2 months & 340 hours & Unpaid (hired) \\
\hline \multirow{3}{*}{$\begin{array}{c}\text { Maggie Intern } \\
7(\mathrm{x} 3)\end{array}$} & 50/week & 6 weeks & 300 hours & Unpaid \\
\hline & 40/week & 6 weeks & 240 hours & Unpaid \\
\hline & 47.5/week & 2 weeks & 95 hours & Unpaid \\
\hline Erica Intern 8 & 42.5/week & 3 months & 510 hours & Paid (hired) \\
\hline \multirow{2}{*}{$\begin{array}{c}\text { Eva Intern } 9 \\
(\mathrm{x} 2)\end{array}$} & 39/week & 2 months & 312 hours & Paid \\
\hline & 39/week & 6 months & 936 hours & Paid \\
\hline
\end{tabular}

